\title{
Monitoramento eletrônico feminino: regalia de uma classe favorecida
}

\author{
Female electronic monitoring: privilege of a favored class
}

\author{
Renata Ceschin Melfi de Macedo ${ }^{1}$ \\ Pontifícia Universidade Católica do Paraná (Curitiba, Paraná, Brasil) \\ renatacmelfi@yahoo.com.br \\ https://orcid.org/0000-0002-4718-2249 \\ Gabriela Saciloto Cramer ${ }^{2}$ \\ Pontifícia Universidade Católica do Paraná (Curitiba, Paraná, Brasil) \\ gabrielascramer@gmail.com
}

Recebido: 17.04 .2020

Aprovado: 29.05.2020

\begin{abstract}
Resumo
A partir de uma pesquisa de campo realizada junto ao Núcleo de Execuções Penais da Defensoria Pública do Paraná - sede Curitiba, no período correspondente a junho de 2019 e março de 2020, procura-se questionar a visão dos operadores do direito acerca do monitoramento eletrônico como uma benesse, privilégio ou regalia aplicada a um seleto grupo em execução de pena: as mulheres. A pesquisa se presta a investigar se a concessão do monitoramento eletrônico às mulheres atende as necessidades e condições específicas dessa parcela da população carcerária ou reproduz as violências de gênero presentes no sistema prisional e arreigadas no machismo estrutural da prática judiciária.
\end{abstract}

Palavras-chave: monitoramento eletrônico. Concessão. Violência de gênero.

\begin{abstract}
Due to a field research beside the Penal Execution core area of the Public Defenders of Paraná - Curitiba headquarters, in the period between July 2019 and March 2020, this paper attempts to investigate the vision of the law operators about the electronic monitoring as a benefaction applied to women - a select group of penal execution. This research lends itself to consider if the concession of the electronic monitoring fit with the female necessities such as with the
\end{abstract}

Como citar esse artigo: MACEDO, Renata Ceschin Melfi de; CRAMER, Gabriela Saciloto. Monitoramento eletrônico feminino: regalia de uma classe favorecida. Revista Brasileira de Pesquisa Jurídica, Avaré, v. 1, n. 2, p. 65-82, maio/ago. 2020. https://doi.org/10.51284/rbpj.01.rcmd

${ }^{1}$ Doutora em Filosofia pela Pontifícia Universidade Católica do Paraná (2018); mestre em Direito das Relações Sociais pela Universidade Federal do Paraná (2004); concluinte do curso sobre problemas fundamentais do direito penal e processual penal junto à Georg-August-Universität Göttingen (2014); professora adjunta de direito penal e prática processual penal junto à Pontifícia Universidade Católica do Paraná; advogada criminalista. enatacmelfi@yahoo.com.br

${ }^{2}$ Graduanda em Direito pela Pontifícia Universidade Católica do Paraná. Pesquisadora-Bolsista (Fundação Araucária) na XXVII edição do PIBIC-SEMIC da PUCPR. gabrielascramer@gmail.com 
specific condition of this segment of the prison population, or if it only reproduces the gender violence existent at the prison system and established with the sexism of the judicial practice. Keywords: electronic monitoring. Concession. Gender Violence.

Sumário: 1. Introdução. 2. O monitoramento eletrônico como regalia. 3. Uma breve centelha de realidade. 4. Estudos de caso: o machismo estrutural presente na prática judiciária. 4.1 Metodologia. 4.2. Exposição dos resultados. 5. Considerações finais. 6. Bibliografia. 7. Anexo A - Dados do monitoramento eletrônico feminino.

Summary: 1. Introduction. 2. The electronic monitoring as a benefaction. 3. A brief understanding of reality. 3. Case Studies: the structural sexism existent on the judicial practice. 4.1 Methodology. 4.2 Export results. 5. Final considerations. 6. Bibliographic references. 7. Attachment $\mathrm{A}-$ Female electronic monitoring data.

\section{Introdução}

O presente artigo tem por objetivo realizar uma análise crítica, por meio de dados e materiais bibliográficos, com relação ao desmazelo das autoridades judiciárias com as mulheres que cumprem pena em monitoramento eletrônico, sob o recorte dos processos de execução que tramitavam perante a antiga Vara de Execução de Penas de Réus ou Vítimas Femininas e de Medidas de Segurança de Curitiba. Apesar do monitoramento eletrônico ser constantemente conceituado (e até mesmo aplaudido) pelos juízos de execução e pelo Ministério Público como um benefício, a realidade demonstra que o sistema prisional brasileiro como um todo acaba por punir e invisibilizar aqueles que já eram socialmente excluídos antes mesmo de sua reclusão ${ }^{3}$.

Desta forma, malgrado as afirmações dos membros do Poder Judiciário, o instituto não pode ser considerado um benefício se reproduz as mazelas e degradações das instituições prisionais, como a diferença de tratamento pautada no gênero, a violação da intimidade e da vida privada, além da estigmatização social e da afronta ao princípio da intranscendência da pena, vez que a monitoração transcende ao usuário e afeta os familiares e as demais pessoas que vivem em seu domicílio ${ }^{4}$. Neste diapasão, o que se verifica é uma vasta quantia de obras que versam sobre as condições desumanas no sistema carcerário, especialmente no tocante às condições específicas do gênero feminino, que constantemente são esquecidas. A situação

\footnotetext{
3 BARCINSKI, Mariana; CÚNICO, Sabrina Daiana. Os efeitos (in)visibilizadores do cárcere: as contradições do sistema prisional. Psicologia, v. 28, n²2, Lisboa: dez. 2014.

4 CARVAlHO, Gisele Mendes de; CORAZZA, Thaís Aline Mazetto. O sistema de monitoramento eletrônico à luz do princípio da dignidade da pessoa humana. Revista dos Tribunais, São Paulo, v. 103, n. 945, p. 197-224, jul. 2014.
} 
é perfeitamente exemplificada nas obras de Dráuzio Varella ${ }^{5}$ e Nana de Queiroz ${ }^{6}$, que narram o cotidiano de mulheres abandonadas por seus familiares e círculo social, constantemente preocupadas com as necessidades de seus filhos, vez que não estão presentes para assisti-los. Ocorre que pouco se fala do cumprimento de pena stricto sensu, justamente em razão do entendimento quase uníssono de que o monitoramento eletrônico é um benefício e uma forma de dar-se efetividade ao princípio da dignidade humana e à ressocialização das pessoas reclusas - finalidade maior da Lei de Execuções Penais.

No entanto, o que sucede quando do cumprimento de pena com monitoramento eletrônico é que as mulheres monitoradas são reinseridas no convívio social em condições iguais ou piores que antes do encarceramento, somadas às decisões e manifestações judiciais que não consideram as necessidades advindas de sua subsistência e nem as questões específicas do gênero feminino, como por exemplo a maternidade. Percebe-se o descaso com as mulheres monitoradas na prática judiciária, portanto, quando o princípio da individualização das penas não é levado em consideração, e muito menos a dupla jornada à qual as mulheres estão expostas em suas vidas.

Isto porque a necessidade de sustento próprio e dos filhos não acompanha as proibições e indeferimentos de pedidos de ampliação do monitoramento eletrônico. Em sede de fundamentação, os magistrados alegam a impossibilidade da expansão do perímetro, pois a concessão de tal direito pressuporia a progressão per saltum. Os membros do Ministério Público opinam pelo indeferimento dos pedidos de ampliação sob o fundamento de que se estas mulheres estivessem reclusas em unidades penitenciárias, tais pedidos seriam impossíveis.

No entanto, o que não é apreciado em juízo é a emergência de tarefas cotidianas como levar e buscar os filhos na escola, o comparecimento a consultas médicas, a procura de emprego, e tantos outros pedidos que não são concedidos. Acrescente a isto os inúmeros casos de agressão domiciliar, nos quais as sentenciadas não veem outro caminho senão o descumprimento dos termos a fim de garantir a sua integridade física e moral, que deveria ser provida e tutelada pelo Estado, mas não é. Pontue-se que o descumprimento dos termos do monitoramento eletrônico, pautado no princípio do livre convencimento do juiz, poderá

\footnotetext{
${ }^{5}$ VARELLA, Drauzio. Prisioneiras. 1 ed. São Paulo: Companhia das Letras, 2017

${ }^{6}$ QUEIROZ, Nana. Presos que menstruam. 9. ed. Rio de Janeiro: Record, 2018.
} 
culminar em falta grave e até mesmo na expedição de mandado de prisão para o cumprimento da pena remanescente em regime inicial fechado.

O que se constata é que, em razão do modelo de sociedade patriarcal, à mulher é conferida uma dupla penalização: pela conduta criminosa e pela falha no seu papel como mulher, mãe e esposa. Este fenômeno ocorre em razão do entendimento de que a prática de crimes é algo da natureza masculina e que as mulheres infratoras possuem apenas um desvio em sua moral, contradizendo sua natureza feminina ${ }^{7}$. esta forma, buscou-se delimitar uma visão efetivamente humana das monitoradas, ao passo que as autoridades judiciárias constantemente desrespeitam as condições específicas do gênero feminino também no cumprimento de pena fora do sistema prisional.

\section{O monitoramento eletrônico como regalia}

A situação do monitoramento eletrônico ainda é extremamente lacunosa não apenas no ambiente normativo. Os estudos sobre o instituto, assim como sua aplicação, são extremamente recentes, haja vista que o monitoramento eletrônico foi inserido no ordenamento jurídico pátrio somente pela Lei 12.158/2010, a qual alterou o texto da LEP (art. 146-A a 146-D), originariamente construído na década de 1980 do século passado.

No início de sua aplicação a discussão versava sobre a possibilidade da utilização além das hipóteses de saída temporária em regime semiaberto e prisão domiciliar ${ }^{8}$, ou se o instituto, previsto como medida cautelar diversa da prisão ${ }^{9}$, deveria ser utilizado apenas nos casos de prisão preventiva. Logo, o desafio inicial consistia em contra argumentar as manifestações do Ministério Público, que foram contrários ao instituto desde o início de sua execução.

Neste sentido é o trabalho ministrado por Vanessa Chiari Gonçalves ${ }^{10}$, o qual teve por foco as manifestações ministeriais quando do início da utilização do instituto na comarca de Porto Alegre. Os juízes de execução da comarca optaram por utilizar-se do monitoramento

\footnotetext{
7 SANTORO, Antonio Eduardo Ramires; PEREIRA, Ana Carolina Antunes. Gênero e Prisão: O encarceramento de mulheres no sistema penitenciário brasileiro pelo crime de tráfico de drogas. Meritum, Belo Horizonte, v. 13, p. 87-112, Jan./Jun. 2018.

${ }^{8}$ Art. 146-B da Lei de Execuções Penais.

${ }^{9}$ Art. 319, IX do Código de Processo Penal.

${ }^{10}$ GONÇALVES, Vanessa Chiari. A prisão domiciliar com monitoramento eletrônico como alternativa ao regime semiaberto: a experiência da comarca de Porto Alegre. Revista Brasileira de Ciências Criminais, v. 143/2018, p. 221-244, Maio/2018.
} 
no regime semiaberto quando da ausência de vagas no sistema prisional, fosse por ser o regime inicial determinado para o cumprimento de pena, ou fosse em razão de progressão de regime. Uma das questões mais problemáticas da situação fora o fato de que os princípios e garantias constitucionais foram utilizados pelo Ministério Público como argumentos contrários à concessão do instituto, fazendo com que os direitos fundamentais dos apenados fossem utilizados contra seus próprios interesses.

A controvérsia da possibilidade de utilização do monitoramento eletrônico no caso de ausência de vagas no sistema carcerário foi solucionada, em partes, pela Súmula Vinculante $\mathrm{n}^{\mathrm{o}} 56$ do Supremo Tribunal Federal, segundo a qual "A falta de estabelecimento penal adequado não autoriza a manutenção do condenado em regime prisional mais gravoso". Com ela, a utilização do monitoramento eletrônico, muito embora ainda lacunosa no ambiente normativo, pôde ser realizada para além das hipóteses previstas na Lei de Execuções Penais, assim como em casos diversos dos de prisão preventiva.

No entanto, se no início da utilização do instituto a altercação eram no sentido de conseguir efetivá-lo, hodiernamente a discussão toma outro importante enfoque: o questionamento de se a vida das monitoradas é realmente tão distinta da vida dentro de instituições prisionais a ponto de o instituto ser considerado um benefício, e se os termos delimitados em juízo devem ser seguidos sem levar em consideração o princípio da individualização das penas apenas porque o cumprimento da pena se dará fora do sistema carcerário.

Conforme se passará a expor, o cotidiano das mulheres monitoradas comprova que o instituto acaba por desrespeitar os princípios ressocializador, da individualização das penas e da dignidade da pessoa humana, em razão de as autoridades judiciais constantemente possuírem o pensamento de que o monitoramento eletrônico por si é um privilégio deveras grandioso às sentenciadas, que suas condições pessoais não precisam ser respeitadas, “devendo as suas circunstâncias (trabalho, filhos, compras) serem adequadas com o regime em que se encontra e não o contrário"11. Outrossim, no sistema judiciário brasileiro, em razão da dupla penalização, do estigma que as mulheres infratoras carregam consigo e da visão do instituto como um benefício, as decisões e manifestações judiciais concernentes ao monitoramento eletrônico são extremamente duras e não levam em consideração a situação

\footnotetext{
11 Manifestação ministerial em sede de contrarrazões de Agravo em Execução nos autos de $\mathrm{n}^{\circ} 0000128$ 11.2019.8.16.0009 (mov. 66.1 do Projudi).
} 
de abuso e violência que estas mulheres enfrentaram em toda a sua vida, até mesmo antes do ingresso no sistema penitenciário.

Ademais, poucos são os casos de mulheres monitoradas cujos pedidos de ampliação do monitoramento ou de recolhimento apenas noturno é concedido. Na grande maioria das vezes, tais pedidos dizem respeito ao sustento e cuidado dos filhos e familiares, bem como pela busca de emprego, tendo-se em conta que a quase totalidade destas mulheres não possuem nenhum auxílio social ou familiar. Os magistrados e membros do Ministério Público efetivam a dupla penalização ao afirmarem que as negativas com relação à modificação dos termos do monitoramento se justificam pelo fato de que, se estas mulheres estivessem reclusas em unidades penitenciárias, pedidos como levar e buscar os filhos na escola não seriam possíveis.

O que se pode constatar, portanto, é que o monitoramento eletrônico realmente é mais benéfico às apenadas apenas em tese. Outrossim o que ocorre na prática judiciária é a demonstração que o instituto apenas reproduz as violências de gênero presentes no sistema prisional, em razão do machismo estrutural presente nas decisões e manifestações judiciais. Tal situação evidencia, portanto, o claro descaso do Estado com relação à visibilidade e inserção social destas mulheres, visto que a ausência de políticas públicas de auferimento de renda, assistência laboral, social e psicológica tem por consequência a reincidência, o uso abusivo de substâncias químicas, a situação de rua, bem como a intranscendência da pena, que afeta os filhos e familiares destas mulheres.

\section{Uma breve centelha de realidade}

Conforme citado anteriormente, o instituto do monitoramento eletrônico ainda é extremamente lacunoso no âmbito normativo, o que faz com que sua aplicação se torne maleável a partir da casuística e fundamentação das decisões e manifestações judiciais. A consequência do preenchimento das lacunas normativas a partir da discricionariedade das autoridades judiciárias não raras vezes acaba por acarretar malefícios consideráveis às sentenciadas: constantemente há a criação de requisitos e entraves subjetivamente construídos, absolutamente dissociados na realidade vivida pelas requerentes. 
Esta situação, conforme descreve Flavia Piovesan ${ }^{12}$, ocorre, pois, por mais que as constituições latino-americanas tenham trazido em seu bojo expansões significativas nos direitos fundamentais, não foram realizadas reformas sociais e normativas profundas aptas à consolidação de seu conteúdo. Segundo a autora, o sistema interamericano tinha uma credibilidade extremamente baixa quando da sua criação e não era esperado pelos países signatários que pudesse causar grandes reformas nas situações de vulnerabilidade e impunidade presentes na região. Assim, muito embora algumas mudanças sejam perceptíveis desde o início da utilização do instituto, ainda não é possível conceituá-lo como uma regalia ou um benefício como fazem as autoridades judiciárias. Até mesmo porque, apesar de propiciar o cumprimento de pena fora dos estabelecimentos prisionais, ainda se trata de uma ferramenta penológica, e, como tal, é extremamente restritiva aos direitos fundamentais.

Outrossim, apesar da existência de um discurso de ressocialização e desencarceramento, a realidade prática da utilização do monitoramento eletrônico é bem distinta. Além de se tratar de uma forma de cumprimento de pena, especificamente no tocante às mulheres monitoradas, não há como falar sobre reinserção social quando tais indivíduos já eram excluídos socialmente, haja vista que a sua condição social, na grande maioria dos casos, já os torna invisíveis perante a sociedade ${ }^{13}$. Segundo informações constantes no Diagnóstico sobre a política de monitoração eletrônica do ano de $2017^{14}$, o total de pessoas monitoradas chega a 51.515 em todo o Brasil. Em apenas 17,19\% dos casos o monitoramento foi utilizado como medida cautelar diversa da prisão. Tal situação faz cair por terra o argumento de que o monitoramento eletrônico é utilizado como forma de desencarceramento, haja vista que na grande maioria das vezes o instituto é utilizado para monitorar pessoas reclusas em unidades prisionais cuja saída temporária fora autorizada, ou para monitorar os sentenciados em prisão domiciliar.

Percebe-se, portanto, que na maioria das situações o instituto do monitoramento eletrônico é utilizado como mais um método de encarceramento em massa, o que, segundo

\footnotetext{
12 PIOVESAN, Flávia. Direitos humanos e o diálogo entre jurisdições. Revista Brasileira de Direito Constitucional - RBDC, n.19, p. 67-93, jan./jun. 2012.

${ }^{13}$ BARCINSKI, Mariana; CÚNICO, Sabrina Daiana. Os efeitos (in)visibilizadores do cárcere: as contradições do sistema prisional. Psicologia, v. 28, n² 2, Lisboa: dez. 2014.

${ }^{14}$ DEPEN. Diagnóstico sobre a política de monitoração eletrônica. Ministério da Segurança Pública. Brasil, 2017. Disponível em: [https://www.br.undp.org/content/brazil/pt/home/library/paz/diagnosticosobre-a-politica-de-monitoracao-eletronica.html]
} 
Daiana Maturano Dias Martil e Rodrigo Ghiringhelli ${ }^{15}$ "apenas perpetua situações de segregação e desigualdade, sob a justificativa da necessidade de aprisionamento para a manutenção da ordem pública". Ademais, conforme apontado por Dünkel, Thiele e Treig ${ }^{16}$, uma possível eficiência dos programas de monitoramento eletrônico depende de um adequado acompanhamento por profissionais como assistentes sociais, terapeutas, entre outros que possam auxiliar o indivíduo em seu processo de reintegração à vida em sociedade.

De acordo com informações prestadas pelo Ministério de Segurança Pública ${ }^{17}$, no entanto, a equipe multiprofissional aparece em $46 \%$ das 24 Unidades Federativas, quais sejam: Acre, Bahia, Ceará, Goiás, Minas Gerais, Mato Grosso, Pará, Pernambuco, Rio Grande do Sul, Roraima e Santa Catarina. A composição da equipe multiprofissional varia nas 11 Unidades Federativas, sendo que apenas Pará, Pernambuco e Roraima apresentam no quadro os profissionais minimamente recomendados pela política nacional de monitoração eletrônica (Assistente Social, Bacharel em Direito e Psicólogo). A composição da equipe multiprofissional aparece reduzida apenas à figura do Assistente Social nos estados do Acre e do Rio Grande do Sul. No Mato Grosso e em Santa Catarina, o Bacharel em Direito é o único profissional elencado enquanto integrante da "equipe multiprofissional". Na Bahia e no Ceará a equipe conta com Assistente Social e Bacharel em Direito. Em Minas Gerais a equipe multiprofissional é composta por Assistente Social e Psicólogo. A situação é deficitária e está longe de ser a ideal. Ellen Rodrigues ${ }^{18}$ bem identifica onde se encontra o cerne da questão:

\begin{abstract}
Há que se ter em conta que, antes se defender o uso do monitoramento eletrônico, assumindo-o como ferramenta capaz de modificar o sistema criminal e penitenciário de um país, é imperioso reconhecer que tal mudança exige antes uma reorientação da própria política criminal, que deve se guiar no sentido do imperativo humanista e na edificação de modelos de controle social que privilegiem a paz social em detrimento da violência.
\end{abstract}

Longe de poder ser conceituado como um apanágio de um grupo seleto, o monitoramento eletrônico se configura como uma modalidade de controle e punição

\footnotetext{
${ }^{15}$ MARTIL, Daiana Maturano Dias; AZEVEDO, Rodrigo Ghiringuelli de. Encarceramento feminino: a (in)eficácia da política criminal enquanto violadora de direitos. Seminário Internacional Fazendo Gênero, 11 \& 13 Women's Worlds Congress, Florianópolis, 2017.

${ }^{16}$ DÜNKEL, Frieder; THIELE, Christoph; TREIG, Judith (Orgs.). "You'll never stand-alone": Electronic monitoring in Germany. European Journal of Probation, v. 9, p. 28-45, 2017.

${ }^{17}$ DEPEN, 2017.

${ }^{18}$ RODRIGUES, Ellen e col. Monitoramento eletrônico de pessoas no brasil à luz da criminologia e do direito comparado. Revista Brasileira de Ciências Criminais, vol. 168, p. 185-223, Jun/2020.
} 
aplicável em virtude dos avanços da tecnologia, pois implica restrição de circulação, horários e impossibilidade de exercício de determinadas atividades.

\section{Estudos de caso: o machismo estrutural presente na prática judiciária}

\subsection{Metodologia}

Os dados aqui apresentados foram coletados em pesquisa de campo realizada no Núcleo de Execuções Penais da Defensoria Pública do Paraná - sede Curitiba, a partir do acesso à planilha de prazos dos Defensores Públicos do setor, no período correspondente a junho de 2019 e março de 2020. Com a obtenção destes processos, cuja característica principal dos apenados é a vulnerabilidade social, foi possível realizar um filtro utilizandose do verbete de pesquisa "monitoramento eletrônico". A partir da aplicação do filtro, cerca de 200 (duzentos) processos cujo objeto é a monitoração eletrônica foram indicados de forma automática pelo sistema.

Foi possível então a separação de 50 (cinquenta) processos de monitoramento eletrônico feminino. Insta ressaltar que tais processos foram escolhidos aleatoriamente, sendo a única determinação em comum o fato de que os prazos conferidos aos Defensores Públicos deveriam versar sobre monitoração eletrônica. A partir da determinação de quais processos seriam analisados, foi elaborada uma tabela para a exposição dos dados obtidos, que segue anexa. A referida planilha contém o número do processo, um resumo do histórico da monitoração eletrônica desde sua concessão até março de 2020 e, por fim, a situação do instituto.

O estudo dos processos, então, foi realizado sob uma perspectiva de gênero, a fim de que se pudesse ser observado, ou não, o desapreço com relação às condições femininas e individuais das mulheres monitoradas na prática judiciária. Para isto, foram observadas as justificativas apresentadas em juízo com relação ao descumprimento dos termos do monitoramento eletrônico, os pareceres emitidos pelo Ministério Público opinando pelo acolhimento ou não de tais justificativas e, por fim, as decisões judiciais determinando a revogação ou a manutenção do instituto, bem como suas fundamentações. Desta forma, o desenvolvimento metodológico do presente artigo foi possível em razão dos fichamentos dos dados coletados em sede de análise processual, em conjunto com a pesquisa descritiva 
anteriormente realizada, que possuíram o objetivo de registrar, analisar e correlacionar fatos ou fenômenos, sem manipulá-los.

\subsection{Exposição dos resultados}

Dos 50 (cinquenta) processos analisados, apenas 08 (oito) casos possuíam o instituto da prisão domiciliar com monitoramento eletrônico vigente até março de 2020. Existiam 16 (dezesseis) casos de regime semiaberto harmonizado vigentes, dos quais 12 (doze) foram deferidos em sede de mutirão carcerário e apenas em 04 (quatro) destes a progressão ao regime semiaberto ensejou o regime semiaberto harmonizado e não a prisão domiciliar.

Apenas 09 (nove) mulheres monitoradas conseguiram a progressão ao regime aberto em sede de mutirão carcerário. Verificou-se a existência de 10 (dez) casos de prisão domiciliar com monitoramento eletrônico revogadas e 05 (cinco) casos de regime semiaberto harmonizado revogados. Ainda, constatou-se 02 (dois) casos de prisão domiciliar suspensos. Em um deles, aguardava-se a prisão da sentenciada e, no outro, a apenada encontrava-se recolhida em unidade prisional aguardando a audiência de justificativa com relação ao descumprimento dos termos.

Da análise dos processos de execução cujo objeto é o monitoramento eletrônico foi possível a constatação de que os pedidos de aumento de perímetro são constantemente negados, ainda que versem sobre a necessidade de sustento e cuidado próprio, dos filhos e familiares. Ademais, quando as mulheres monitoradas conseguem algum emprego, normalmente são atividades laborais como panfletagem, diarista, cuidadora, caixa, balconista, manicure ou outros incapazes de, por si sós, garantir a subsistência da apenada e seus familiares. E, por óbvio, tais empregos são realizados fora da residência das apenadas, impossibilitando assim o cumprimento da pena em prisão domiciliar com monitoramento eletrônico sem que haja o descumprimento dos termos.

Aqui cabe ressaltar uma grande questão da diferença pautada no gênero na comarca de Curitiba: os homens cujos processos de execução tramitam nesta comarca, quando progridem ao regime semiaberto, dão início ao cumprimento do regime na Colônia Penal Agrícola. Em sede de mutirão carcerário - projeto que possui como objetivo a humanização e desafogamento do sistema prisional - aos homens é concedida a chamada "harmonização do regime semiaberto", em que eles possuem a oportunidade de terminar o cumprimento do regime semiaberto com a tornozeleira eletrônica, apenas com recolhimento noturno, quando 
muito. Em contrapartida, como o Centro de Regime Semiaberto Feminino de Curitiba (CRAF) fora interditado em 2014 em razão da ausência de vagas em comparação com a quantidade de mulheres em regime semiaberto, a estas mulheres é determinado o cumprimento, desde logo, em prisão domiciliar com monitoramento eletrônico. Ocorre que, ao contrário do que as autoridades judiciárias acreditam, tal instituto acaba por ser extremamente maléfico para as mulheres.

Isto porque, na prática judiciária, o que se verifica é que estas mulheres apenas são reinseridas no convívio social em condições iguais ou piores do que antes de sua reclusão. Desta forma, as mulheres monitoradas continuam excluídas da sociedade, com a diferença de que possuem o estigma da tornozeleira eletrônica acrescido a todas as responsabilidades cotidianas decorrentes de seus deveres não contemplados nos termos definidos pelo poder punitivo. Assim, como o regime semiaberto harmonizado enseja apenas o recolhimento noturno e simplifica o cumprimento da pena ainda que com as questões específicas do gênero feminino e da maternidade, os dados expostos a seguir versarão sobre o instituto da prisão domiciliar com monitoramento eletrônico, vez que nele é mais facilmente identificada a desatenção ao princípio da individualização das penas.

Da análise dos autos executórios, o que se verifica é que quando as justificativas apresentadas pelas sentenciadas são acolhidas, tais acolhimentos ensejam a advertência de que um novo descumprimento dos termos poderá levar à regressão de regime. Ocorre que as necessidades advindas do trabalho externo e do cuidado com filhos e familiares não cessam com o "perdão" conferido em juízo. Desta forma, não há como tais mulheres deixarem de cometer infrações sem que os termos para o cumprimento da prisão domiciliar com monitoramento eletrônico sejam flexibilizados, como ocorre no cumprimento do regime semiaberto harmonizado masculino. Este foi o caso dos autos de $\mathrm{n}^{\circ}$ 001481838.2016.8.16.0013, no qual houve o descumprimento dos termos do monitoramento pois era necessário que a sentenciada se dirigisse com frequência ao supermercado para comprar produtos essenciais para seus 06 filhos que residiam com ela, bem como levá-los e buscá-los na escola. Muito embora uma justificativa neste teor tenha sido acolhida em juízo com a anuência do Ministério Público, os termos da monitoração não foram ampliados, o que resultou na revogação do instituto pelo reiterado descumprimento dos termos.

Situação semelhante ocorreu nos autos de $n^{\circ}$ 0000128-11.2019.8.16.0009, nos quais a sentenciada solicitou permissão para trabalho externo, bem como para buscar e levar seus filhos na escola. Muito embora o pleito de trabalho externo tenha sido deferido, o juízo alegou 
que, segundo o Art. 35 do $\mathrm{CP}$, os presos têm direito a trabalho externo no período diurno, mas que a sentenciada apenas cumpria pena em prisão domiciliar em razão da ausência do CRAF e que, se estivesse em unidade destinada ao semiaberto feminino, o pleito de levar e buscar os filhos na escola nunca seria possível. A situação das necessidades advindas da maternidade é recorrente, como podem exemplificar os autos de $\mathrm{n}^{\circ}$ 001673558.2017.8.16.0013. Neste caso, após serem juntadas informações com relação ao descumprimento dos termos da monitoração, a sentenciada apresentou justificativa informando que seu filho estava no educandário de Piraquara e, que, quando retornou à residência, foi determinado que ele deveria frequentar o CRAS duas vezes na semana. Como era menor de idade, coube à sentenciada acompanhá-lo. Ainda que a justificativa tenha sido acolhida, o Ministério Público requereu fosse a apenada advertida de que novas infrações poderiam ensejar à regressão de regime, argumentando que "a sentenciada deveria adequarse ao atual regime mais benéfico, e não ao contrário".

$\mathrm{O}$ contexto das mulheres monitoradas também dificulta muito a busca por empregos. Nos autos de $\mathrm{n}^{\mathrm{o}}$ 0001381-34.2019.8.16.0009, a sentenciada informou que as informações de descumprimento dos termos se deram pois estaria trabalhando como manicure na casa de suas clientes. A justificativa fora acolhida, mas a apenada fora advertida que novos descumprimentos ensejariam a regressão ao regime fechado. Novas infrações foram acostadas aos autos e o Ministério Público, sob o argumento de que não haveria a comprovação de que a sentenciada realmente estaria laborando naqueles momentos, requereu a revogação do instituto. Assim, corroborando com o parquet, o juízo determinou a revogação da prisão domiciliar com monitoramento eletrônico, com a posterior remoção da apenada ao regime fechado.

Somado a este contexto de impossibilidade de sustento próprio e dos filhos, de incapacidade laboral ante a necessidade de cumprimento dos termos impostos pelo juízo, e de vulnerabilidade social, as mulheres monitoradas ainda precisam lidar com o fenômeno do abandono feminino no cárcere que, segundo Jessika Borges Lima dos Santos e Márcio Santana da Silva ${ }^{19}$, se volta contra a mulher encarcerada em razão de seu estigma de transgressora e tem como consequência todas as discriminações sofridas, sem que haja uma investigação acerca da motivação destas mulheres ao praticarem condutas criminosas. Isto

\footnotetext{
${ }^{19}$ SANTOS, Jessika Borges Lima; SILVA, Márcio Santana da. Encarceramento feminino: reflexões acerca do abandono afetivo e fatores associados. Revista Psicologia Política, São Paulo, v. 19, n. 46, set./dez. 2019.
} 
significa dizer que, em todas as esferas de cumprimento de pena a mulher é duplamente penalizada, inclusive por seus familiares, sem que haja, por parte do Estado, um estudo aprofundado sobre a criminalidade ou a criação de políticas públicas que efetivamente ressocializem estas mulheres. Esta questão pôde ser exemplificada nos autos de nº 0006026 30.2017.8.16.0088, nos quais a ausência de sinal na tornozeleira eletrônica ensejou na regressão ao regime fechado. Quando da designação da audiência de justificativa, a sentenciada informou que havia deixado registrado em juízo o endereço de uma amiga que havia se prontificado a lhe ajudar, mas que tal amiga se mudou sem avisá-la e ela ficou sem ter onde morar ou carregar a tornozeleira.

Além do fenômeno do abandono feminino no cárcere, as mulheres monitoradas precisam enfrentar outro desafio: o da violência doméstica. Nos autos de $\mathrm{n}^{\circ}$ 000091137.2018.8.16.0009, foram juntadas informações de infrações do monitoramento eletrônico e o juízo determinou a suspensão do instituto e a expedição de mandado de prisão. A sentenciada, apresentou justificativa nos autos informando estaria recebendo ameaças de seu companheiro e que, para assegurar sua integridade física, se viu obrigada a deixar o endereço registrado em juízo, bem como que rompeu o equipamento por medo de ser recolhida novamente, principalmente porque na época estaria grávida. O Ministério Público, então, se manifestou pelo não acolhimento da justificativa e determinação de audiência de justificativa. Após a realização da audiência, o juízo determinou a revogação do instituto e a regressão da sentenciada ao regime fechado, sob o argumento de que "as alegações da sentenciada apresentadas na audiência, não tem o condão de justificar o rompimento de sua tornozeleira eletrônica" ${ }^{20}$.

Verificou-se ainda não haver sido a primeira vez que o argumento acima fora utilizado, haja vista que nos autos de $\mathrm{n}^{\mathrm{o}}$ 0003074-53.2019.8.16.0009, a apenada acostou no processo laudo médico apto a comprovar sua tentativa de suicídio, e o Ministério Público se manifestou no sentido de que os documentos apresentados pela sentenciada também não possuíam o condão de eximir sua responsabilidade. Por estes e outros motivos, a situação das mulheres monitoradas é de extrema vulnerabilidade social, havendo casos em que o descumprimento dos termos do monitoramento eletrônico se dá em razão de a apenada ser moradora de rua, como nos autos de $n^{\circ}$ 0008489-42.2019.8.16.0033. Neste processo, os pertences da sentenciada foram furtados, inclusive o carregador da tornozeleira eletrônica.

${ }^{20}$ Mov. 130.1 do Projudi. 
Ainda assim, o juízo revogou o instituto e determinou a regressão da sentenciada ao regime fechado, quase que penalizando de forma expressa a apenada em razão de sua situação de rua.

A prisão domiciliar com monitoramento eletrônico por razões de saúde também não se trata de exceção à regra da inflexibilidade das decisões e manifestações judiciais. Nos autos de $n^{\circ}$ 0000750-03.2017.8.16.0190, a sentenciada fora colocada em prisão domiciliar após o diretor do Complexo Médico Penal a incapacidade de tratamento da patologia de que é acometida a executada - insuficiência renal crônica dialítica - no sistema. Ao serem juntadas infrações do monitoramento eletrônico, a sentenciada apresentou justificativa solicitando a ampliação dos termos para que pudesse comparecer à hemodiálise 03 vezes na semana, bem como para buscar medicamentos esporadicamente. o Ministério Público, então, se manifestou no sentido de que não há como se falar em ampliação do monitoramento em razão de o regime da sentenciada ser o fechado, bem como que ela deveria solicitar em juízo o comparecimento a consultas e exames, ainda que o instituto apenas tenha sido concedido para que a sentenciada recebesse o devido tratamento médico.

Assim, pôde-se constatar, na prática judiciária, o descaso com as situações individuais das mulheres em prisão domiciliar com monitoramento eletrônico, somado ao entendimento quase uníssono de que o cumprimento da pena deve ser sobreposto a toda e qualquer responsabilidade pessoal que elas venham a ter, mesmo se tais responsabilidades digam respeito a sua subsistência ou ao cuidado com os filhos dependentes. Mais do que nunca atestou-se que a realidade do encarceramento feminino se sobrepõe a qualquer discurso de livre arbítrio $^{21}$, haja vista que, principalmente nos casos de prisão domiciliar com monitoramento eletrônico, a reincidência em faltas graves consistentes no descumprimento dos termos do monitoramento eletrônico - que ensejam na regressão ao regime fechado - é necessária para que tais mulheres ao menos tentem deixar o enquadramento de vítimas e passem a ter o controle de sua existência, do seu sustento e do sustento de sua família.

Ainda, com relação ao instituto do monitoramento eletrônico, principalmente no que concerne aos processos que tramitavam perante a antiga Vara de Execução de Penas de Réus ou Vítimas Femininas e de Medidas de Segurança de Curitiba, o que se nota é que a situação

\footnotetext{
${ }^{21}$ CARRILHO, Iara Gonçalves. A realidade do encarceramento feminino se sobrepõe a qualquer discurso de livre arbítrio. Justificando, 2018. Disponível em:

[http://www.justificando.com/2018/04/14/a-realidade-do-encarceramento-feminino-se-sobrepoe-a-qualquerdiscurso-de-livre-arbitrio/] Acesso em 22 set. 2020.
} 
não é diferente do que ocorre no cumprimento de pena lato sensu, muito embora pouco se discuta sobre o instituto, em razão de o cumprimento de pena na residência ser visto como mais benéfico do que o cumprimento de pena na unidade penitenciária. Por meio da literatura estudada, bem como pela análise dos dados obtidos foi possível constatar também que o cumprimento da pena em prisão domiciliar com monitoramento eletrônico é inviável para as mulheres, em razão da dupla jornada à qual estão expostas. Conforme já citado no presente artigo, estas mulheres ficam tão excluídas socialmente em razão do instituto do que ficavam nas unidades penitenciárias e antes do encarceramento, em razão da situação de vulnerabilidade que presenciam em toda a sua vida. Um outro fato que merece relevância sobre o assunto é a constante inaplicação do princípio da intranscendência da pena. Nas palavras de Daniele Amanda Silva ${ }^{22}$ :

\begin{abstract}
A reclusão masculina é acompanhada da certeza de um responsável pelos cuidados dos filhos - que na, grande maioria, este cargo é ocupado pela mãe das crianças que, além de oferecer todo apoio aos filhos, continua mantendo o contato com o marido e também possibilita a proximidade entre ele e seus descendentes. Já o encarceramento feminino é caracterizado pela imprecisão quanto ao destino dos filhos, uma vez que o pai não se responsabiliza pelo cuidado dos mesmos, ou não tem como fazê-lo por também estar em situação de aprisionamento, com isso, juntamente com a reclusão da mulher, inicia-se um processo de inquietude e preocupação quanto ao estabelecimento de redes de proteção social ou de solidariedade para abrigar estas crianças enquanto perdurar a reclusão materna.
\end{abstract}

É necessário que se reflita sobre o trecho acima não apenas quando da reclusão em unidades penitenciárias, mas também, e principalmente, quando do instituto do monitoramento eletrônico. Isto porque, ainda que o encarceramento traga as rupturas sociais e familiares estudadas pela referida autora, as responsabilidades destas mulheres são incumbidas a outras pessoas. No caso do instituto estudado, a situação é alterada de forma que as mulheres monitoradas, ficam incumbidas do sustento próprio e de seus filhos enquanto fiscalizadas pelo Poder Punitivo e adstritas aos seus termos.

Constata-se, portanto, a inexistência da tão falada ressocialização, haja vista que estas mulheres, já sobrecarregadas pela vida levada pelo gênero feminino, ainda permanecem sob a vigilância do Estado, que não leva em consideração o princípio da individualização das penas e apenas enxerga tais mulheres como transgressoras da ordem e dos bons costumes, conferindo a elas uma dupla penalização.

\footnotetext{
22 SILVA, Amanda Daniele. Mãe/mulher atrás das grades: A realidade imposta pelo cárcere à família monoparental feminina. São Paulo: Cultura Acadêmica, 2015.
} 


\section{Considerações finais}

O que se conclui com o presente trabalho, é que, muito embora a legislação pátria seja promissora no que diz respeito aos Direitos Humanos e à diminuição das diferenças e violências pautadas no gênero, a América Latina ostenta o maior grau de desigualdade social, fato que influencia diretamente na garantia dos direitos fundamentais ${ }^{23}$. Assim, muito embora haja uma vasta quantidade de obras que versem sobre o sistema prisional, há uma parcela de mulheres que permanece ainda mais nas sombras: as monitoradas. No que concerne ao instituto do monitoramento eletrônico, nota-se um reflexo da sociedade patriarcal em que estamos inseridos no sistema punitivo, haja vista que o este também se sobrepõe às necessidades básicas femininas quando da utilização do instituto. Sabe-se que a violência de gênero está presente em todos os momentos do cotidiano, independentemente do contexto no qual as mulheres estejam inseridas. Imagine-se que Simone de Beauvoir ${ }^{24}$, branca, europeia e de classe média alta, sentiu a necessidade de analisar a situação da mulher na sociedade, e chegar-se-á a conclusão que a mulher latino-americana, parda ou negra, de classe baixa e ainda condenada por sentença penal transitada em julgado trava incessantes lutas para se fazer reconhecer a sua legitimidade como ser humano detentora de direitos.

Com relação ao cumprimento de pena stricto sensu, as decisões judiciais com relação ao instituto são inflexíveis desde o momento da sua concessão. O tema foi abordado por Priscilla Placha Sá, Heloisa Vieira Simões e Priscilla Conti Bortolomeu ${ }^{25}$, em seu texto que aborda o paradoxo entre as Regras de Bangkok, das quais o Brasil é signatário face às decisões denegatórias de prisão domiciliar com monitoramento eletrônico para a população encarcerada gestante ou com filhos menores. Com o estudo, restou muito clara a dupla penalização à qual as mulheres estão submetidas: em razão do cometimento do crime e em razão da falha no seu papel como mulheres, bem como o descaso do poder judiciário do estado do Paraná com relação às necessidades femininas e à tutela constitucional da família e aos princípios da intranscendência e da individualização das penas. Verifica-se, portanto, a rigidez com a qual as mulheres são tratadas no sistema judiciário e prisional, não sendo tal

\footnotetext{
23 PIOVESAN, Flávia. Direitos humanos e o diálogo entre jurisdições. Revista Brasileira de Direito Constitucional - RBDC, n.19, p. 67-93, jan./jun. 2012.

${ }^{24}$ BEAUVOIR, Simone de. O segundo sexo: fatos e mitos. 5 ed. Rio de Janeiro: Nova Fronteira,2019.

${ }^{25}$ SÁ, Priscilla P. et. al. Quem te prende e não te solta: as regras de Bangkok e a análise de decisões denegatórias do poder judiciário do estado do Paraná em pedidos de prisão domiciliar para mulheres presidiárias gestantes e com crianças. Rev.Brasileira de Ciências Criminais, v. 151, p. 383-416, Jan. / 2019.
} 
rigidez exclusiva do cumprimento de pena dentro nas unidades prisionais. Na realidade, o que se pôde constatar é que, como o monitoramento eletrônico é, em tese, mais benéfico do que o cumprimento de pena na unidade penitenciária, a diferença e a violência de gênero, o machismo estrutural nas decisões e manifestações judiciais, a dupla penalização e a inobservância dos princípios constitucionais e dos direitos fundamentais estão tão presentes quanto quando do cumprimento da pena em unidades penitenciárias.

Por fim, constata-se a urgência de tal discussão, a fim de que as mulheres monitoradas tenham suas necessidades atendidas e um cumprimento de pena efetivamente igualitário e humanitário. Com a verificação de que mulheres encarceradas possuem necessidades concernentes ao gênero feminino também quando no cumprimento de pena nos referidos termos, poder-se-á transformar a visão que comumente se tem sobre tais mulheres. Desta forma, antes de se olhar para elas como transgressoras das leis, morais e bons costumes, deve-se criar o hábito de enxergá-las como mães, esposas e seres humanos.

\section{Bibliografia}

BARCINSKI, Mariana; CÚNICO, Sabrina Daiana. Os efeitos (in)visibilizadores do cárcere: as contradições do sistema prisional. Psicologia, v. 28, n.2, Lisboa: dez. 2014.

CARRILHO, Iara Gonçalves. A realidade do encarceramento feminino se sobrepõe a qualquer discurso de livre arbítrio. Justificando, 2018. Disponível em:

[http://www.justificando.com/2018/04/14/a-realidade-do-encarceramento-feminino-sesobrepoe-a-qualquer-discurso-de-livre-arbitrio/] Acesso em 22 set. 2020.

CARVALHO, Gisele Mendes de; CORAZZA, Thaís Aline Mazetto. O sistema de monitoramento eletrônico à luz do princípio da dignidade da pessoa humana. Revista dos Tribunais, São Paulo, v. 103, n. 945, p. 197-224, jul. 2014.

DEPEN. Diagnóstico sobre a política de monitoração eletrônica. Ministério da Segurança Pública. $\quad$ Brasil, $2017 . \quad$ Disponível em:[https://www.br.undp.org/content/brazil/pt/home/library/paz/diagnostico-sobre-apolitica-de-monitoracao-eletronica.html]

DOTTA, A. G.; et al. Direitos da mulher: maternidade no cárcere. In: EVINCI. Curitiba: UniBrasil, 2020b. v.5. p.193. [https://portaldeperiodicos.unibrasil.com.br/index.php/anaisevinci/article/view/4982]

DOTTA, A. G.; et al. Infraestrutura carcerária e direitos da mulher encarcerada: um estudo analítico a partir dos dados do INFOPEN 2017. In: EVINCI. Curitiba: UniBrasil, 2020a. v.5. p.42.

[https://portaldeperiodicos.unibrasil.com.br/index.php/anaisevinci/article/view/4548] 
DOTTA, A. G.; et al. Perfil da população prisional brasileira: pessoas com deficiência In: In: $\quad$ EVINCI. Curitiba: UniBrasil, 2020. [https://portaldeperiodicos.unibrasil.com.br/index.php/anaisevinci/article/view/4553]

DOTTA, A. G.; et al. Perfil da população prisional feminina: uma análise a partir de cor e raça. In: EVINCI. Curitiba: UniBrasil, 2020e. v.5. p.45. [https://portaldeperiodicos.unibrasil.com.br/index.php/anaisevinci/article/view/4552]

DOTTA, A. G.; et al. Perfil da população prisional feminina. In: EVINCI. UniBrasil, 2020d. v.5.

p.172: [http://https://portaldeperiodicos.unibrasil.com.br/index.php/anaisevinci/article/view/4927]

DOTTA, A. G.; et al. Perfil da população prisional no Brasil: um estudo a partir dos dados compilados pelo INFOPEN 2017 In: EVINCI. Curitiba: UniBrasil, 2020f. v.5. [https://portaldeperiodicos.unibrasil.com.br/index.php/anaisevinci/article/view/4543]

DOTTA, A. G.; et al. Tempo de pena da população carcerária feminina. In: Evinci, $\begin{array}{llll}\text { Curitiba: } & 2020 . & \text { v.5. } & \text { p.47. }\end{array}$ [https://portaldeperiodicos.unibrasil.com.br/index.php/anaisevinci/article/view/4554]

DOTTA, A. G.; et al.; Infraestrutura e direito das mulheres: um estudo de caso a partir dos dados do INFOPEN de 2016 In: EVINCI. Curitiba: UniBrasil, 2020c. v.5. p.39. [https://portaldeperiodicos.unibrasil.com.br/index.php/anaisevinci/article/view/4546]

DÜNKEL, Frieder; THIELE, Christoph; TREIG, Judith (Orgs.). "You'll never stand-alone": Electronic monitoring in Germany. European Journal of Probation, v. 9, p. 28-45, 2017.

GONÇALVES, Vanessa Chiari. A prisão domiciliar com monitoramento eletrônico como alternativa ao regime semiaberto: a experiência da comarca de Porto Alegre. Revista Brasileira de Ciências Criminais, v. 143/2018, p. 221-244, Maio/2018.

MARTIL, Daiana Maturano Dias; AZEVEDO, Rodrigo Ghiringuelli de. Encarceramento feminino: a (in)eficácia da política criminal enquanto violadora de direitos. Seminário Internacional Fazendo Gênero, 11 \& 13 Women's Worlds Congress, Florianópolis, 2017.

PIOVESAN, Flávia. Direitos humanos e o diálogo entre jurisdições. Revista Brasileira de Direito Constitucional - RBDC, n.19, p. 67-93, jan./jun. 2012.

QUEIROZ, Nana. Presos que menstruam. 9. ed. Rio de Janeiro: Record, 2018.

RODRIGUES, Ellen e col. Monitoramento eletrônico de pessoas no brasil à luz da criminologia e do direito comparado. Revista Brasileira de Ciências Criminais, vol. 168, p. 185-223, Jun/2020.

SÁ, Priscilla P. et. al. Quem te prende e não te solta: as regras de Bangkok e a análise de decisões denegatórias do poder judiciário do estado do Paraná em pedidos de prisão domiciliar para mulheres presidiárias gestantes e com crianças. Rev.Bras. de Ciências Criminais, v.151, p.383-416, jan. 2019.

SANTORO, Antonio Eduardo Ramires; PEREIRA, Ana Carolina Antunes. Gênero e Prisão: $O$ encarceramento de mulheres no sistema penitenciário brasileiro pelo crime de tráfico de drogas. Meritum, Belo Horizonte, v. 13, p. 87-112, Jan./Jun. 2018. 
SANTOS, Jessika Borges Lima; SILVA, Márcio Santana da. Encarceramento feminino: reflexões acerca do abandono afetivo e fatores associados. Ver. Psi. Política, v. 19, n. 46, set./dez. 2019.

SILVA, Amanda Daniele. Mãe/mulher atrás das grades: A realidade imposta pelo cárcere à família monoparental feminina. São Paulo: Cultura Acadêmica, 2015.

VARELLA, Drauzio. Prisioneiras. São Paulo: Companhia das Letras, 2017.

Como citar esse artigo: MACEDO, Renata Ceschin Melfi de; CRAMER, Gabriela Saciloto. Monitoramento eletrônico feminino: regalia de uma classe favorecida. Revista Brasileira de Pesquisa Jurídica, Avaré, v. 1, n. 2, p. 65-82, maio/ago. 2020. https://doi.org/10.51284/rbpj.01.rcmd 